\title{
Carbonation of Chrysotile under Subcritical Conditions
}

\author{
Kyoung Won Ryu, Soo Chun Chae and Young Nam Jang* \\ Korea Institute of Geoscience and Mineral Resources, Geological and Environmental Research Department, \\ Gwang-no 92, Yuseong-gu, Daejeon 305-350, Korea
}

The carbonation of chrysotile $\left[\mathrm{Mg}_{3} \mathrm{Si}_{4} \mathrm{O}_{10}(\mathrm{OH})_{4}\right]$ under subcritical conditions was experimentally investigated in alkali solution, and the chemical composition as well as the morphological and structural changes were discussed. The starting material was hydrothermally treated by aqueous direct carbonation at a temperature of $100^{\circ} \mathrm{C}$ and $\mathrm{CO}_{2}$ partial pressure range of $0.5 \mathrm{MPa} \sim 4 \mathrm{MPa}$ at pH 13 . Highly crystalline magnesite was synthesized under a $\mathrm{CO}_{2}$ partial pressure of $3 \mathrm{MPa}$. The carbonation rate increased at the proportional rate according to the applied $\mathrm{CO}_{2}$ pressure to approximately $57 \%$. The surface morphology of chrysotile changed from the fibrous form to a round or oval shape at the initial stage and subsequently to magnesite with well-faceted rhombohedral planes.

The dissolution rate of $\mathrm{Mg}$ was higher than $\mathrm{Si}$, such that the $\mathrm{Mg}$ : Si ratio of chrysotile decreased from 1.56 to $0.4 \sim 0.6$ as the reaction time increased. The resultant silica-rich layer of the reaction product ultimately changed through the Mg-depleted skeletal phase to the amorphous silica phase. The experimental results suggest that carbonation in alkali solution under subcritical conditions is of great significance because an excessive amount of acid and alkali reagents can be eliminated in the carbonation process. [doi:10.2320/matertrans.M2011155]

(Received May 25, 2011; Accepted July 21, 2011; Published August 31, 2011)

Keywords: chrysotile, subcritical condition, carbon dioxide, carbonation, magnesite

\section{Introduction}

Mineral carbonation has been recognized as a promising option for emission reduction of $\mathrm{CO}_{2}$ as a mitigation measure of global warming. ${ }^{1)}$ Carbon sequestration and utilization processes via carbonation reaction of materials containing alkaline earth metals such as calcium and magnesium have been developed. The utilization of magnesium and calcium silicate for the sequestration of carbon dioxide is already beyond the proof-of-concept stage, and it has great potential to sequester substantial amounts of $\mathrm{CO}_{2}$. This sequestration process offers a safe and permanent method of $\mathrm{CO}_{2}$ disposal, since $\mathrm{CO}_{2}$ is chemically incorporated into the mineral and is immobilized. ${ }^{2,3)}$ Magnesium-bearing deposits are frequently richer than deposits containing calcium oxide. Thus, magnesium silicate such as serpentine is more attractive for $\mathrm{CO}_{2}$ sequestration.

The most comprehensively studied process for carbonation is aqueous carbonation involving leaching or dissolution of silicate in liquid media. ${ }^{4-6)}$ In a previous work, many researchers found that acids were much more efficient at leaching magnesium from serpentine than bases were. ${ }^{7)}$ However, the effect of carbonation for most silicate minerals is generally very weak in acidic to neutral solutions, but may be notable in alkaline conditions. Moreover, the $\mathrm{pH}$ swing process might to be required to achieve a higher conversion of the $\mathrm{CO}_{2}$ mineral carbonation. Therefore, the high energy cost due to the use of excessive amounts of acid and alkali reagents is a major obstacle to the practical applications of mineral carbonation. ${ }^{8)}$

In this study, the leaching of serpentine and carbonation to design a more effective mineral sequestration process were carried out in alkaline solution at an appropriate temperature and under subcritical conditions.

*Corresponding author, E-mail: crystal@kigam.re.kr

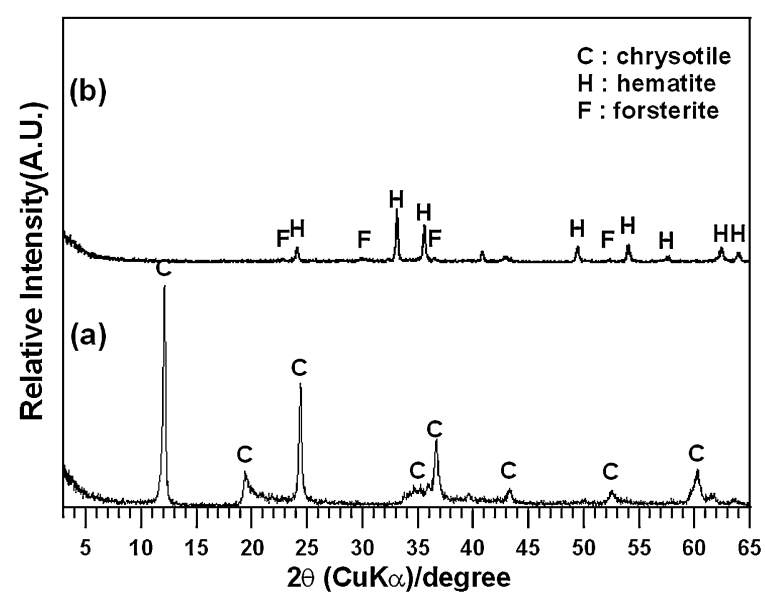

Fig. 1 XRD patterns of raw material (a) and heated chrysotile (b).

\section{Experiment}

\subsection{Materials}

The mineral chrysotile $\left[\mathrm{Mg}_{3} \mathrm{Si}_{4} \mathrm{O}_{10}(\mathrm{OH})_{4}\right]$ used in this study was obtained from Chungyang, Korea. X-ray diffraction (XRD) data indicated that the starting material was pure chrysotile (Fig. 1(a)). Thermal activation of hydrated Mgsilicate species was accomplished by the addition of a heat treatment stage in the mineral pretreatment process, with an objective of rendering the crystal structures unstable by dehydroxylation. Thermogravimetry/differential thermal analysis (TG-DTA) was used to investigate the heatactivation process of chrysotile, and Fig. 2 shows its TGDTA profile. Its thermal decomposition follows a two-stage sequence where the first weight loss is attributed to absorbed water $\left(71^{\circ} \mathrm{C}\right)$ and the second is attributed to dehydroxylation $\left(642^{\circ} \mathrm{C}\right)$. During the heat treatment, the transformation of chrysotile into forsterite $\left(\mathrm{Mg}_{2} \mathrm{SiO}_{4}\right)$ and enstatite $\left(\mathrm{MgSiO}_{3}\right)$ was achieved at $818^{\circ} \mathrm{C}$. In the range of $550 \sim 708^{\circ} \mathrm{C}$, an 
Table 1 Chemical composition of heat-treated chrysotile from Chungyang, Korea.

\begin{tabular}{lccccccccccc}
\hline Component & $\mathrm{SiO}_{2}$ & $\mathrm{MgO}$ & $\mathrm{CaO}$ & $\mathrm{Al}_{2} \mathrm{O}_{3}$ & $\mathrm{Na}_{2} \mathrm{O}$ & $\mathrm{K}_{2} \mathrm{O}$ & $\mathrm{Fe}_{2} \mathrm{O}_{3}$ & $\mathrm{MnO}$ & $\mathrm{TiO}_{2}$ & $\mathrm{Total}$ \\
\hline$\%$ & 43.3 & 39.5 & 0.05 & 1.55 & 0.08 & 0.02 & 6.77 & 0.06 & 0.03 & 87.45 \\
\hline
\end{tabular}

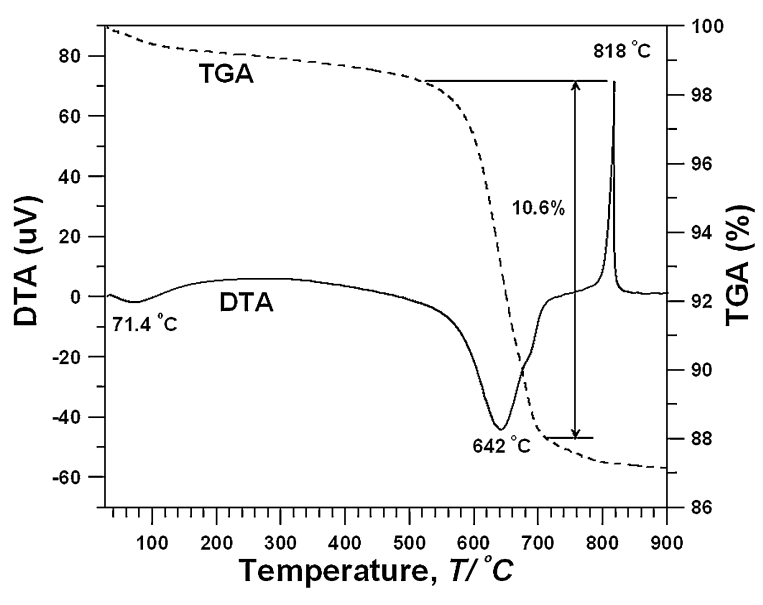

Fig. 2 TGA-DTA patterns of chrysotile.

additional 10.6 mass $\%$ loss can be ascribed to the loss of $\mathrm{OH}$ groups. Hence, chrysotile used in this study contains 13.6 mass\% of water. This result has been researched in several previous studies. ${ }^{9,10)}$ Therefore, the starting material for the carbonation was heated at $650^{\circ} \mathrm{C}$ for $2 \mathrm{~h}$ in atmosphere. After activation, the chrysotile became metachrysotile, and forsterite and hematite $\left(\mathrm{Fe}_{2} \mathrm{O}_{3}\right)$ peaks appeared (Fig. 1(b)). The major components of heated chrysotile were $39.5 \% \mathrm{MgO}$ and $43.3 \% \mathrm{SiO}_{2}$, whereas the major impurities were $6.8 \% \mathrm{Fe}_{2} \mathrm{O}_{3}, 1.6 \% \mathrm{Al}_{2} \mathrm{O}_{3}$, and $0.05 \% \mathrm{CaO}$ (Table 1).

\subsection{Methods}

The starting material for carbonation was crushed in a Jetmill to grains that could pass through a $<325$ mesh sieve. The grain size was measured by a particle-size analyzer (KMC-1B, KME Co.). The chemical composition of chrysotile was analyzed by inductively coupled plasma atomic emission spectroscopy (ICP-AES) (JY 38 Plus, France Jobin Yvon).

All carbonation experiments were performed in a $1 \mathrm{~L}$ coldseal-type stainless vessel. The following experimental conditions were maintained unless otherwise specified: the reaction temperature was $100^{\circ} \mathrm{C}$, the reaction time was $1 \mathrm{~h}$, and the $\mathrm{CO}_{2}$ partial pressure was varied from 0.5 to $4 \mathrm{MPa}$. The initial alkalinity of the solution was adjusted at $\mathrm{pH} \sim 13$, and the final $\mathrm{pH}$ was always $\sim 7.5$. The $\mathrm{pH}$ of the solution was controlled by adding $1 \mathrm{M} \mathrm{NaOH}$ solution (OCI, extra pure). $0.5 \mathrm{M} \mathrm{NaHCO}_{3}$ was added as a more effective $\mathrm{CO}_{2}$ carrier. The mineral/water/liquid $\mathrm{CO}_{2}$ mixture was continuously agitated to prevent settling of the solid.

After carbonation, the reaction products were collected and analyzed by XRD (X'pert MPD X-ray diffractometer with graphite-monochromatized $\mathrm{Cuk} \alpha$ radiation, Phillips Co). The microstructure of the synthesized products was examined by a transmission electron microscope (TEM, JEM 2200FS, JEOL) coupled with an energy dispersive X-ray spectrometer (EDS, Oxford) and a scanning electron micro- scope (FE-SEM, S-4700, Hitachi). TEM samples were dispersed in distilled water by an ultrasonic probe. They were air dried after they were placed on a holder. Scanning electron microscopy (SEM) examination was carried out at a working voltage of $15 \mathrm{KeV}$. The sample powder was sedimented on a $\mathrm{Cu}$-microgrid and coated with osmium tetraoxide $\left(\mathrm{OsO}_{4}\right)$.

The carbonation rate of chrysotile to magnesite was calculated by thermogravimetric analysis (TG-DTA) at atmospheric pressure (DTG-60H, Shimazu). Profiles were obtained for a temperature range of $30-900^{\circ} \mathrm{C}$ with a constant heating rate of $10^{\circ} \mathrm{C} / \mathrm{min}$ under argon.

\section{Results and Discussion}

The carbonation reaction of heated chrysotile was successfully investigated under subcritical conditions. The FTIR spectra provided valuable information on the chrysotile carbonation reaction (Fig. 3). The IR spectrum of chrysotile exhibits three well-defined spectral regions. The first band appears in the $3800-3600 \mathrm{~cm}^{-1}$ region, the second appears in the $1200-800 \mathrm{~cm}^{-1}$, and third region included the bands below $800 \mathrm{~cm}^{-1}$. Two bands observed at $3688 \mathrm{~cm}^{-1}$ and $3645 \mathrm{~cm}^{-1}$ are assigned to in-phase outer and inner $\mathrm{Mg}-\mathrm{OH}$ stretch, respectively. Two broad bands observed at $3440 \mathrm{~cm}^{-1}$ and $1638 \mathrm{~cm}^{-1}$ are due to the stretching and bending vibrations of water molecules adsorbed to the chrysotile tubes. ${ }^{11,12)}$ Two bands at 1078 and $952 \mathrm{~cm}^{-1}$ are attributed to the Si-O-Si stretching vibrations perpendicular to the basal plane and the $\mathrm{Si}-\mathrm{O}-\mathrm{Si}$ vibrations in the basal plane, respectively. ${ }^{11,13)}$ A strong IR band at $613 \mathrm{~cm}^{-1}$ attributed to inner $\mathrm{Mg}-\mathrm{OH}$ vibration and a shoulder at $555 \mathrm{~cm}^{-1}$ arising from the perpendicular $\mathrm{Si}-\mathrm{O}$ bending vibration were observed. The IR band at $442 \mathrm{~cm}^{-1}$ is assigned to the bending vibration of Si-O-Si (Fig. 3(a)). ${ }^{14)}$

After heat treatment of chrysotile, especially the IR band at $3688 \mathrm{~cm}^{-1}$ assigned to the surface $\mathrm{Mg}-\mathrm{OH}$ stretch and bands at 1078,952 , and $442 \mathrm{~cm}^{-1}$ attributed to the $\mathrm{SiO}_{4}$ tetrahedra vibration became considerably weak and exhibited broadening. These results can be ascribed to the loss of $\mathrm{OH}$ groups by heat treatment of chrysotile (Fig. 3(b)). After carbonation under a $\mathrm{CO}_{2}$ partial pressure $0.5 \mathrm{MPa}$, the spectrum of magnesite included a peak resulting from the out-of-plane $\mathrm{CO}_{3}{ }^{2-}$ band at $885 \mathrm{~cm}^{-1}\left(v_{2}\right)$. A characteristic double peak at 1423 and $1485 \mathrm{~cm}^{-1}$ appeared. The position and shape of the peaks correspond to the $\mathrm{CO}_{3}{ }^{2-}$ group in silicate glasses after dissolution of $\mathrm{CO}_{2}$ (Fig. 3(c)). ${ }^{15,16)}$ Under $1 \mathrm{MPa}$, the in-plane $\mathrm{CO}_{3}{ }^{2-}$ band at $747 \mathrm{~cm}^{-1}\left(v_{4}\right)$ was observed anew, and the double peaks at 1423 and $1485 \mathrm{~cm}^{-1}$ decreased (Fig. 3(d)). With regards to the IR patterns, a well ordered magnesite was successfully obtained when reaction $\mathrm{CO}_{2}$ partial pressure was increased to $1.5 \mathrm{MPa}$. After the carbonation under $1.5 \mathrm{MPa}$, the asymmetric $\mathrm{CO}_{3}{ }^{2-}$ stretch at $1431 \mathrm{~cm}^{-1}\left(v_{3}\right)$ was formed newly (Fig. 3(e)). As $\mathrm{CO}_{2}$ partial 


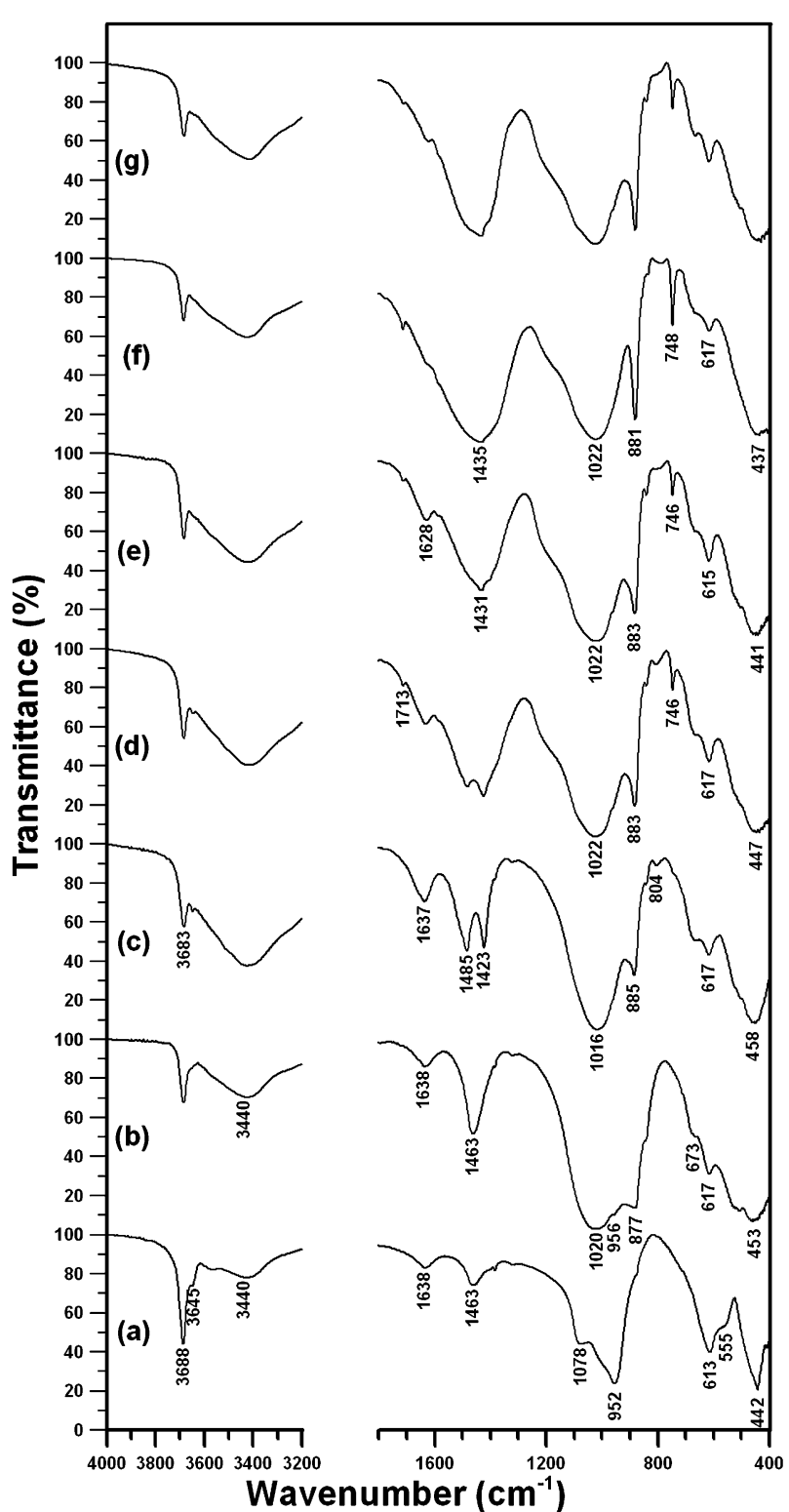

Fig. 3 FT-IR spectra of starting material (a), heated chrysotile (b) and carbonation products under various $\mathrm{CO}_{2}$ partial pressures: $0.5 \mathrm{MPa}$ (c), $1 \mathrm{MPa}$ (d), 1.5 MPa (e), $2 \mathrm{MPa}$ (f).

pressure increased, the peaks of $v_{2}, v_{3}, v_{4}$ were exhibited at $1435,881,748 \mathrm{~cm}^{-1}$, respectively and peak intensity of magnesite became stronger. Highly crystalline magnesite was synthesized under $3 \mathrm{MPa}$ (Fig. 3(f)), too.

The surface morphology was examined by SEM (Fig. 4). Most of the chrysotile was composed of acicular and cylindrical-like structure of the fibrils, which were under $100 \mathrm{~nm}$ (Fig. 4(a)). After the reaction under 0.5 MPa, magnesite crystals showed irregular morphology of a rather round shape surrounded by unreacted chrysotile. Moreover, the unreacted chrysotile crystals partially exhibited a lathtype morphology, but most of them were changed to an oval shape (Fig. 4(b)) although their chemical compositions coincided with that of chrysotile. After the reaction under $1 \mathrm{MPa}$, magnesite crystals exhibited irregular corners/edges (Fig. 4(c)), and under 1.5 Mpa, well-faceted rhombohedral magnesite was exhibited, with the crystal size of magnesite of approximately $2 \mu \mathrm{m}$ (Fig. 4(d)). When the $\mathrm{CO}_{2}$ partial pressure was increased up to $2.5 \mathrm{MPa}$, most of magnesite particles were found to be twin crystals, and unreacted chrysotile decreased considerably (Fig. 4(e)). Under $3 \mathrm{MPa}$, highly crystalline magnesite was observed (Fig. 4(f)). When the $\mathrm{CO}_{2}$ partial pressure increased above $3.5 \mathrm{MPa}$, however, most of the edges and corners of the carbonate particles were eroded (Fig. 4(g)).

The extent of carbonation was determined by calcining the final product using TGA, as the weight change during calcination corresponds to the amount of $\mathrm{CO}_{2}$ captured by carbonation (Fig. 5). The maximum carbonation rate was found to be approximately $57 \%$ at $100^{\circ} \mathrm{C}$ under $3 \mathrm{MPa}$. TGA analysis revealed that the amount of transformed magnesite increased rapidly up to $1 \mathrm{MPa}$. It increased at somewhat proportional rate to approximately $57 \%$ after carbonation up to $3 \mathrm{MPa}$, after which point it decreased slightly. From this result, it may be inferred that the dissociation of carbonic acids occurred with an increase in the $\mathrm{CO}_{2}$ partial pressure above $3.5 \mathrm{MPa}$, and the $\mathrm{pH}$ of the solution was decreased.

Many studies on carbonation in the literature reported that mineral dissolution in the aqueous phase can be increased in the presence of anions, protons, organic ligands, and weak acids. Maroto-Valter et al. $(2005)^{10)}$ researched that the steam-activated serpentine underwent a $60 \%$ conversion to magnesite at $155^{\circ} \mathrm{C}$ and $12.6 \mathrm{MPa}$ after $1 \mathrm{~h}$ in distilled water. $\mathrm{O}^{\prime}$ Connor et al. $(2005)^{17)}$ proposed that the maximum carbonation rate achieved was no more than $57 \%$ at $155^{\circ} \mathrm{C}$ and $12 \mathrm{MPa}$. Considering that the carbonation rate in this study was obtained at $100^{\circ} \mathrm{C}$ under a $\mathrm{CO}_{2}$ partial pressure of $3 \mathrm{MPa}$ in alkali solution, we find that our results are comparable to the results of Maroto-Valter et al. and O'Connor et al.; our results suggest that carbonation in alkali solution is of great significance because excessive amounts of acid and alkali reagents can be eliminated in the carbonation process, and conversion under subcritical conditions may be applied practically.

The chemical composition as well as the morphological and structural changes related to the dissolution of chrysotile under $\mathrm{CO}_{2}$ at a pressure of $3 \mathrm{MPa}$ at reaction times from $15 \mathrm{~min}$ to $1 \mathrm{~h}$ was examined by TEM (Fig. 6). The TEM image of heated chrysotile maintained its typical morphology and periodic array of lattice points (Fig. 6(a)). EDS data of heated chrysotile showed a $\mathrm{Mg}: \mathrm{Si}$ ratio of 1.56. After the reaction for only $15 \mathrm{~min}$, the skeletal image of chrysotile surrounded by a succession of a silica-rich layer was shown, and the $\mathrm{Mg}$ content around the inner core of chrysotile was higher than that of the outside layers. The $\mathrm{Mg}$ : Si ratio was in the range of $1.0 \sim 1.2$ (Fig. 6(b)). As the reaction time increased up to $30 \mathrm{~min}$, the amount of $\mathrm{Mg}$ released from chrysotile increased, and the silica-rich layer exhibited parallel structural lines. Accordingly, a large number of $\mathrm{Mg}$ ions were leached out, and the range of $\mathrm{Mg}: \mathrm{Si}$ ratio was $0.4 \sim 0.6$ (Fig. 6(c)). After the reaction for $1 \mathrm{~h}$, an amorphous silica phase was observed, which seemed to be separated from the host as the final stage of dissolution (Fig. 6(d)).

$\mathrm{Si}$ release during the dissolution was less than that of $\mathrm{Mg}$; i.e., dissolution was non-stoichiometric for cations $\mathrm{Si}$ and $\mathrm{Mg}$. The breakdown of Si-O-Si- $+2 \mathrm{OH}+2 \mathrm{Si}-\mathrm{O}-$ is active in alkali solution at the initial stage. ${ }^{18-20)}$ As the reaction 


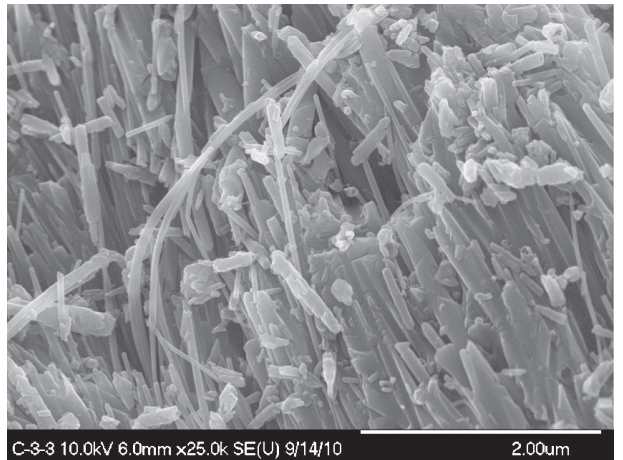

(a)

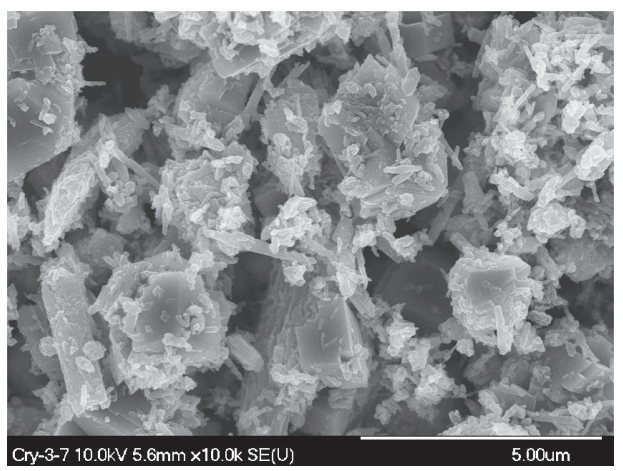

(c)

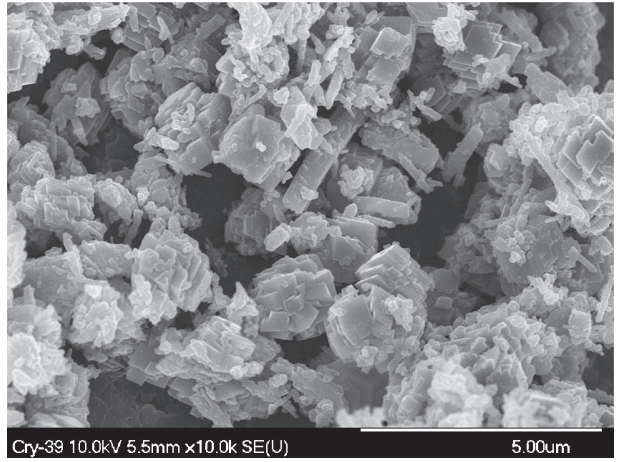

(e)

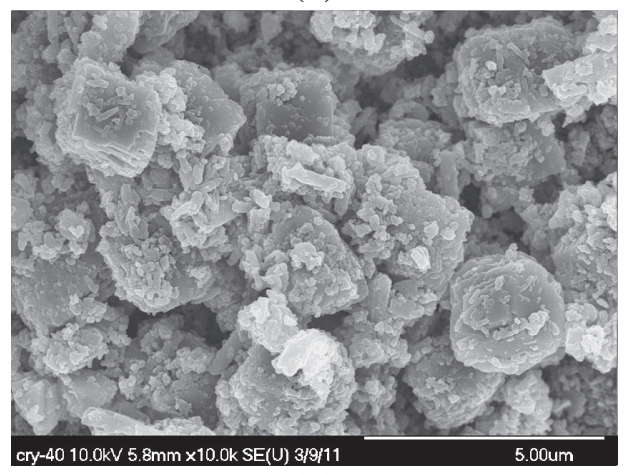

(g)

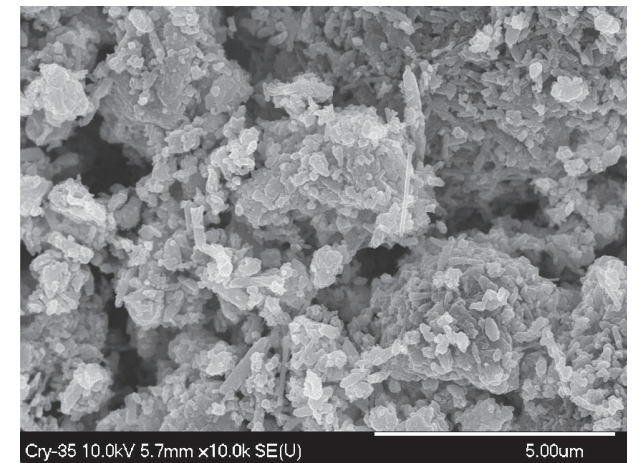

(b)

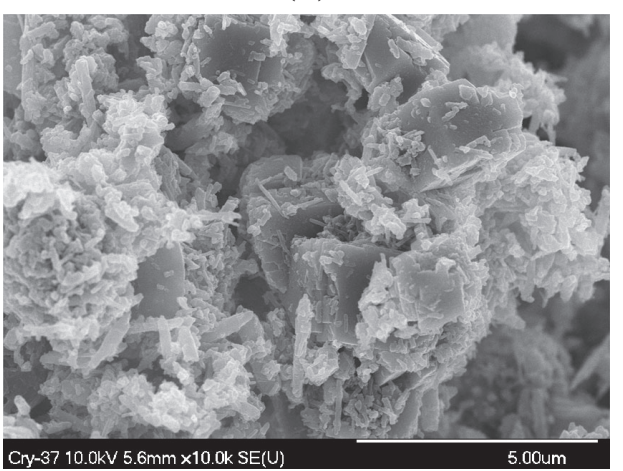

(d)

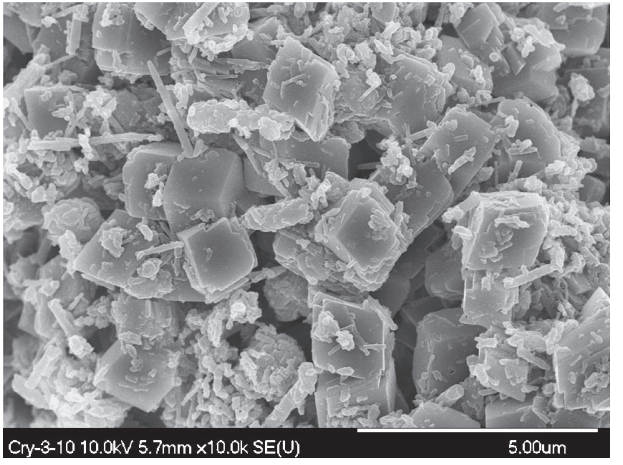

(f)

Fig. 4 SEM image of chrysotile (a) and carbonation product according to $\mathrm{CO}_{2}$ partial pressure: $0.5 \mathrm{MPa}$ (b), $1 \mathrm{MPa}$ (c), $1.5 \mathrm{MPa}$ (d), 2.5 MPa (e), $3 \mathrm{MPa}(\mathrm{f}), 3.5 \mathrm{MPa}(\mathrm{g})$.

progressed, the $\mathrm{pH}$ of the alkali solution decreased because the dissolved $\mathrm{CO}_{2}$ formed carbonic acid, which likely dissociated to $\mathrm{H}^{+}$and $\mathrm{HCO}_{3}{ }^{21)}$ Moreover, as the proton concentration increased, the protonation of the oxygen atoms polarized and weakened the $\mathrm{Mg}-\mathrm{O}-\mathrm{Si}$ bonds, ${ }^{3,22}$ thereby facilitating the preferential removal of magnesium atoms from the crystal lattice and leaving the skeletal structure of the Si-rich layers. Eventually, the complete dissolution of $\mathrm{Mg}$ from chrysotile leads to the presence of only the amorphous silica phase. This mechanism provides the reason why the carbonation rate in alkali conditions is higher than that in a neutral or acidic solution. 


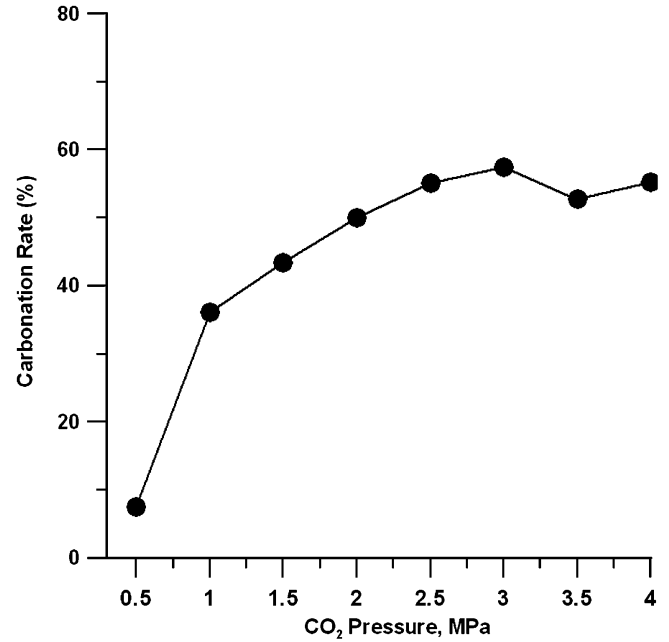

Fig. 5 Carbonation rate of chrysotile at various subcritical conditions.

\section{Conclusion}

Chrysotile carbonation was experimentally performed under subcritical conditions in alkali solution. As the reaction proceeded, the surface morphology of chrysotile changed from an acicular and a cylindrical-like form to a round or oval shape at the initial stage and to a highly crystalline magnesite with well-faceted rhombohedral planes after carbonation. The carbonation rate increased proportionally according to the applied $\mathrm{CO}_{2}$ pressure to approximately $57 \%$ at $3 \mathrm{MPa}$.

The dissolution rate of $\mathrm{Mg}$ was higher than $\mathrm{Si}$, such that the $\mathrm{Mg}$ : Si ratio of the reacted chrysotile decreased from 1.56 to $0.4 \sim 0.6$ as the reaction time increased under a pressure of $3 \mathrm{MPa}$, and the amorphous silica phase was observed at the final stage of dissolution. $\mathrm{Mg}$ was released preferentially from the crystal lattice in alkali solution and left the skeletal structure of Si-rich layers.

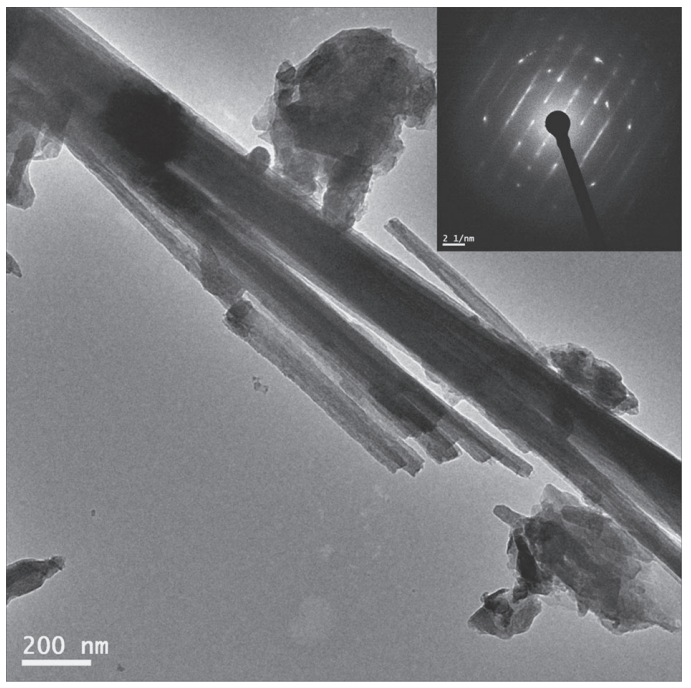

(a)

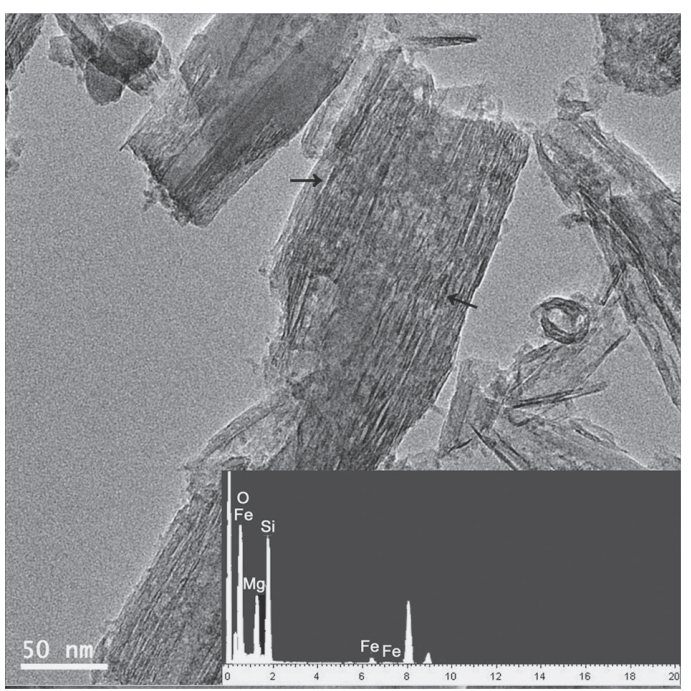

(c)

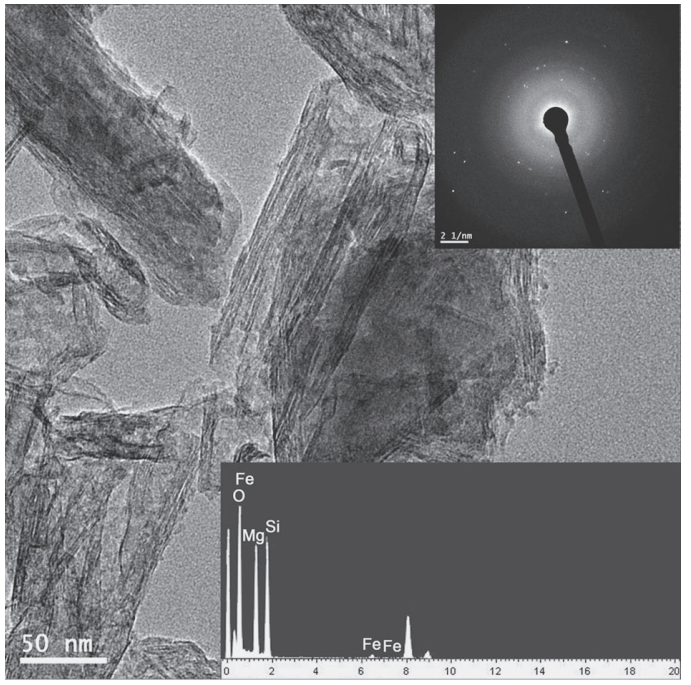

(b)

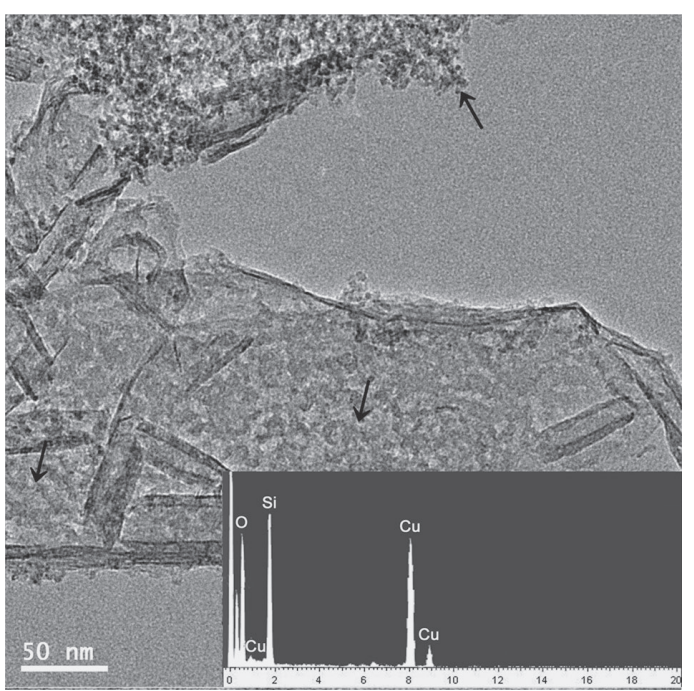

(d)

Fig. 6 TEM image of chrysotile obtained after reaction in alkali solution: heated chrysotile (a), $15 \mathrm{~min}$ (b), $30 \mathrm{~min}(\mathrm{c}), 1 \mathrm{~h}(\mathrm{~d})$. 


\section{Acknowledgements}

This work was supported by the "Utilization and Sequestration of $\mathrm{CO}_{2}$ by Using Industrial Minerals" program (KIGAM) funded by the Ministry of Knowledge Economy of Korea. We also wish to thank the KBSI Jeonju Center for the electron microscope analysis.

\section{REFERENCES}

1) S. Teir, R. Kuusik, C. J. Fogelholm and R. Zevenhoven: Int. J. Miner. Process. 85 (2007) 1-15.

2) A. H. A. Park and L. S. Fan: Chem. Eng. Sci. 59 (2004) 5241-5247.

3) G. Alexander, M. M. Maroto-Valer and P. Gafarova-Aksoy: Fuel 86 (2007) 273-281.

4) B. Metz, O. Davidson, H. C. Coninck, M. Loos and L. A. Meyer: Carbon Dioxide Capture and Storage, IPCC Working Group III of the Intergovernmental Panel on Climate Change, (Cambridge University, 2005) Chapter 7.

5) D. Daval, I. Martinez, J. Corvisier and N. Findling: Chem. Geol. 265 (2009) 63-78.

6) M. M. Maroto-Valer, Y. Zhang, M. E. Kuchta, J. M. Andrésen and D. J. Fauth: US Patent US2005/0002847.

7) S. Tier, H. Revitizer, S. Eloneva, C. J. Fogelholm and R. Zevenhoven: Int. Miner. Process. 83 (2007) 36-46.

8) M. G. Lee, K. W. Ryu, Y. N. Jang, W. B. Kim and J. H. Bang: Mater.
Trans. 52 (2011) 235-238.

9) W. Li, W. Li, B. Li and Z. Bai: Chem. Eng. Res. Des. 87 (2009) 210215.

10) M. M. Marto-Valter, D. J. Fauth, M. E. Kuchta, Y. Zhang and J. M. Andrésen: Fuel Process. Tech. 86 (2005) 1627-1645.

11) G. Anbalagan, G. Sivakumar, A. R. Prabakaran and S. Gunasekaran: Vibrational Spectrosc. 52 (2010) 122-127.

12) L. Wang, A. Lu, C. Wang, X. Zheng, D. Zhao and R. Liu: J. Colloid Interf. Sci. 295 (2006) 436-439.

13) C. Viti and M. Mellini: Eur. J. Mineral. 9 (1997) 585.

14) E. Foresti, M. Gazzano, A. F. Gualteiri, I. G. Lesci, B. Lunelli, G. Pecchini, E. Renna and N. Rovrei: Anal. Bioanal. Chem. 376 (2003) 653-658.

15) E. V. Kalinkina, A. M. Kalinkin, W. Forsling and V. N. Makarov: Int. J. Miner. Process. 61 (2001) 289-299.

16) G. Fine and E. Stolper: Earth Planet. Sci. 76 (1985/1986) 263-278.

17) W. K. O’Connor, D. C. Dahlin, G. E. Rush, S. J. Gerdemann, L. R. Penner and D. N. Nilsen: The report of the US Department of Energy, DOE/ARC-TR-04-002 (2004).

18) P. V. Brandy and J. V. Walther: Geochim. Cosmohim. Acta 53 (1989) 2823-2830.

19) O. S. Pokrovsky and J. Schott: Cosmohim. Acta 19 (2000) 3313-3325.

20) D. C. Golden, J. B. Dixon, H. Shadfan and L. A. Kippenberger: Clays Clay Miner. 33 (1985) 44-50.

21) A. Berg and S. A. Banwart: Chem. Geol. 163 (2000) 25-42.

22) W. Stumm and J. J. Morgan: Aquatic chemistry: chemical equilibria and rates in natural waters, 3rd ed. New York, (Wiley-Interscience Publication, 1996) 